\title{
Prospects and Challenges of Using Coagulation-Flocculation Method in the Treatment of Effluents
}

\author{
Kingsley Ogemdi Iwuozor
}

\section{A R T I C L E I N F O \\ Received: 13 December 2018 \\ Revised: 2 January 2019 \\ Accepted: 18 January 2019 \\ Available online: 27 January 2019}

\section{K E Y W O R D S}

Effluents

Coagulation

Flocculation

Coagulants

Flocs

\section{A B S T R A C T}

Wastewaters from chemical industries are characterized by the presence of heavy metallic ions, chemical contaminant and turbidity. Exposure to lead (Pb), for example, is recognized as a major risk factor for several human diseases, and the structure of industrial ecological systems have made exposure to $\mathrm{Pb}$ unavoidable for most people alive today. The removal of these toxic metals and contaminants from industrial wastewater is a matter of great interest in the field of water pollution, which is a serious cause of water degradation. Coagulation-flocculation is a widely used method for wastewater treatment especially if the wastewater is discharged into surface water. Coagulation/flocculation is a commonly used process in water and wastewater treatment in which compounds such as ferric chloride and/or polymer are added to wastewater in order to destabilize the colloidal materials and cause the small particles to agglomerate into larger settle able flocs. Therefore, the futuristic use as well as the present demerits of this process is necessary for the treatment of effluents.

\section{G R A P H I C A L A B S T R A C T}
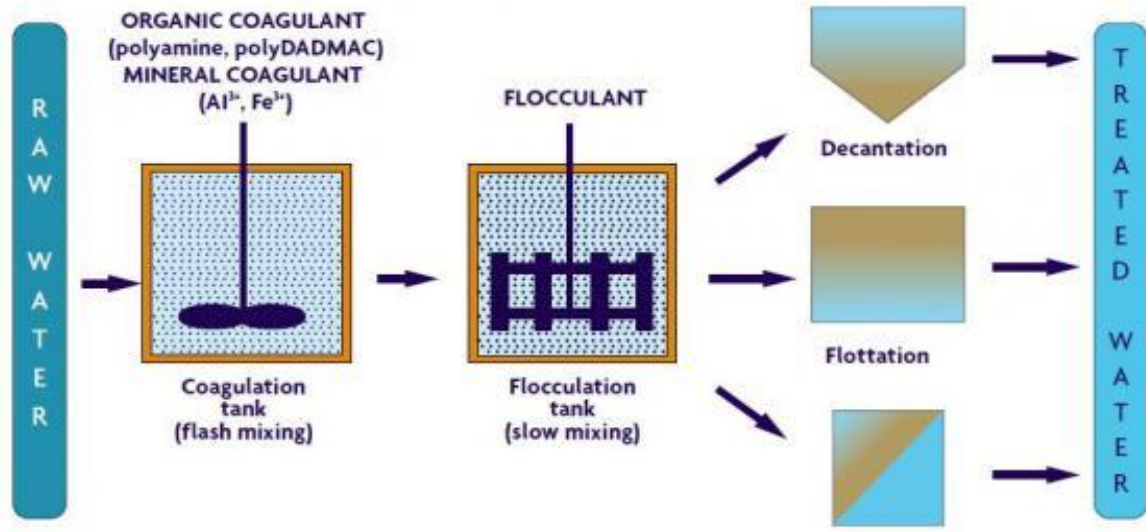

Filtration

*Corresponding author's E-mail address: kingsleyiwuozor5@gmail.com, Tel.: +2347034810425

Department of pure and industrial chemistry, Nnamdi Azikiwe University, Awka, Nigeria. 


\section{Introduction}

Industrialization has led to pollution and consequently environmental degradation due to the release of pollutants to water bodies, land and/or air. One of these pollutant sources is Industrial wastewater. Many industries consume fresh water and release wastewater as exhaust [1]. Wastewater is not just one of the main causes of irreversible damages to the environmental balances but also contributing to the depletion of fresh water reserves in this planet. Wastewaters from industries differ very much in both flow and pollution strength. This makes it difficult to assign fixed values to their constituents. Generally, industrial waste waters contain suspended, colloidal and dissolved (mineral and organic) solids, may be either excessively acid or alkaline and may contain high or low concentrations of colored matter. These wastes typically contain inert, organic or toxic materials and sometimes pathogenic bacteria. As a result of large quantities of water been used by industries, treatment and reuse of wastewaters, at least, to a level safe for disposal have become absolute necessity in order to avoid pollution of fresh water bodies [1].

Several wastewater treatment methods are available as on date in order to ensure good quality effluent before disposal into the municipal sewer systems. The wastewaters vary in terms of the pollutant composition depending on the origin of the industry. The disposal of such effluents in the environment will lead to surface and groundwater contamination: increase in chemical oxygen demand, eutrophication, ecosystem imbalance and human health risks.

Particulate impurities in water result from land erosion, pickup of minerals, and the decay of vegetation. Additional impurities are added by airborne contamination, industrial discharges, and by animal wastes. Thus, surface water sources, polluted by man and nature, are likely to contain suspended and dissolved organic and inorganic material, and biological forms such as bacteria and plankton.

These particulates, commonly called suspended solids, cover a broad range of sizes. Larger sized particles such as sand and heavy silts can be removed from water by slowing down the flow to allow for simple gravity settling. These particles are often called settle-able solids.

Settling of larger sized particles occurs naturally when surface water is stored for a sufficient period of time in a reservoir or a lake. Smaller sized particles, such as bacteria and fine clays and silts, do not readily settle and treatment is required to produce larger 
particles that are settle-able. These smaller particles are often called non-settle able solids or colloidal matter [1].

The purpose of coagulation and flocculation is to remove particulate impurities, especially non-settleable solids and colour from the water being treated. Non-settleable particles in water are removed by the use of coagulating chemicals. In the coagulation process, chemicals are added which will initially cause the particles to become destabilized and clump together. These particles gather together to form larger particles in the flocculation process. It is a commonly used physico-chemical method in the treatment of metal bearing industrial wastewater because it removes colloidal particles, some soluble compounds and very fine solid suspensions initially present in the wastewater by destabilizing and forming flocs. This process destabilizes the colloidal suspension of the particles with coagulants and then causes the particles to agglomerate with flocculants. After that, it accelerates separation and, thereby, clarifies the effluents [1].

High operating costs due to the use of chemical substances and high amount of sludge and its disposal costs are shown as the important disadvantages of chemical treatment. Therefore, researchers have focused on new alternative methods to reduce chemical usage by improving discharge standard with adding low cost natural substance. Clay minerals are natural substances used in wastewater treatment and have high ion exchange capacity, absorption, and catalysis properties as well as natural and low-cost materials. Some researchers reported that clay minerals can be preferable coagulant aid for removal of toxic compounds, pesticide, herbicide, heavy metals and color removal [1].

Recovery and reuse of industrial effluent are effective means for sustainable industrial development. But there is no single process capable of sufficient treatment, mainly due to the complex nature of the effluent. To get treated water with reliable quality several treatment techniques such as adsorption coupled with electro-coagulation, coagulation-flocculation coupled with membrane process, chemical coagulation coupled with ion exchange are being used.

Lin and Liu conducted a continuous process of combined ozonation and chemical coagulation for treatment of dye containing wastewater. This combined treatment was seen to be very effective. It was observed that complete de-colourization of the wastewater was achieved by ozonation, whilst chemical coagulation was responsible for removing the dissolved organic compounds and solid suspensions producing in a high percentage of COD (chemical oxygen demand) removal [3]. 
Riera-Torres and Gutiérrez-Bouzán used a coagulation-flocculation process in combination with nano-filtration technique for textile waste water treatment. It was found that over $98 \%$ of color removal could be achieved using this combined process [4]. A wide range of wastewater treatment techniques having some associated advantages and disadvantages are prevailing. Most commonly wastewater treatments involve biological treatment such as nitrification, de-nitrification and phosphorus removal, physio-chemical treatment such as adsorption, ion exchange, precipitation, reverse osmosis, coagulation, and electro-coagulation [1].

Some researchers have demonstrated that the use of natural coagulants is a promising approach in industrial wastewater treatment. For instance, Krishna, R. and Sahu, O. used natural polymeric coagulant (chitosan) to treat chemical oxygen demand (COD) and colour in a soap and detergent industry wastewater. The results they obtained showed that chitosan was very effective in treating the wastewater. Also, they were able to achieve maximum COD and colour reductions of $83 \%$ and $90 \%$ respectively [5].

Patil C. and Hugar M. investigated the effectiveness of four different natural coagulants, namely T. foenum-graecum,
Moringa oleifera, Cicer arietinum and Dolichos lablab to remove COD and turbidity from industrial dairy wastewater. At the optimum dosage and $\mathrm{pH}$, the turbidity removal efficiencies of M.oleifera, Dolichos lablab, T. foenum-graecum and Cicer arietinum were obtained to be $61.60 \%$, $71.74 \%, 58.20 \%$ and $78.33 \%$ while COD reduction efficiencies of these coagulants were estimated to be $65.0 \%, 75 \%, 62.5 \%$ and $83 \%$, respectively. Based on the results obtained from the work, it was concluded that, among the coagulants considered in the work, Cicer arietinum was the most effective in treating dairy wastewater [6].

Prodanovic et al., studied the coagulation efficiency of common bean extract in treatment of different distillery wastewaters and found that the best achieved efficiencies of organic matter removal were $68.8 \%$ for juice extraction wastewater at $\mathrm{pH}$ of 8.50 with coagulant dose of $5 \mathrm{~mL} / \mathrm{L}$, and $60 \%$ for molasses wastewater at the original $\mathrm{pH}$ of this stillage (5.40) with the same dose. They concluded that natural coagulants extracted from common bean could be used successfully for organic matter removal from extraction juice wastewater and molasses wastewater instead of centrifugation [7].

Also, Kazi T. and Virupakshi A. used Cicer arietinum, Moringa oleifera, and Cactus to 
treat turbidity and COD in tannery wastewater by varying dosage of these coagulants and $\mathrm{pH}$. They discovered that 0.1 g/ $500 \mathrm{~mL}$ Cicer arietinum, 0.3 g/ $500 \mathrm{~mL}$ Moringa oleifera and $0.2 \mathrm{~g} / 500 \mathrm{~mL}$ cactus and $\mathrm{pH}$ of 5.5, 4.5 and 5.5 respectively were the optimum parameters for the wastewater treatment. Their results also indicated that all the three coagulants investigated were promising in treating the pollutants since the turbidity reduction efficiencies for all of them were observed to fall within the range of $78-82 \%$ while that of COD was in the range of 75-90\%. However, Cicer arietinum was found to be the most effective in treating tannery wastewater with maximum turbidity and COD removal of 81.02 and $90 \%$, respectively [8].

Fatehah et al., investigated the efficiency of using tapioca starch as coagulant in the treatment of semiconductor wastewater by varying the dosage of the coagulant and retention time, and they observed that variation of tapioca starch dosage highly influenced the COD and turbidity removal. The results obtained in their work further revealed that the optimum turbidity reduction was $99 \%$ at a settling time of 30 min with dosage of $0.1 \mathrm{~g} / \mathrm{L}$ and that of COD was achieved to be $87 \%$ after $60 \mathrm{~min}$ of retention time and $0.1 \mathrm{~g} / \mathrm{L}$ of dosage. They also discovered that high coagulant dosages between 0.8-1.0 $\mathrm{g} / \mathrm{L}$ reduced the total suspended solids (TSS) concentration from 188 to $10.9 \mathrm{mg} / \mathrm{L}$ at retention time between 50 to 60 minutes [9].

Abdelaal A.M. used bentonitic clay as a solid natural coagulant. The study was carried out on two types of wastewater. The first was acidic wastewater from mining characterized as water clarity from $15-20 \%$, COD 27-35.5 mg/L pH 2.9-4.1, SS -193-197.3 $\mathrm{mg} / \mathrm{L}$ and some heavy metals; the second was oily wastewater characterized as water clarity $-22.5 \%$, COD $-77.0 \mathrm{~g} / \mathrm{L}$, SS of 300 $\mathrm{mg} / \mathrm{L}$, and oil products of $9.0 \mathrm{~g} / \mathrm{L}$. Some chemicals were also used in the study; they were cationic type flocculants of high molecular weight with the bentonitic clay as coagulant and constant $\mathrm{pH}$ of 7.5 at temperature of $25{ }^{\circ} \mathrm{C}$. The process accomplished in a number of systems by Jar test and evaluated by measuring the water clarity, COD, oil content and percent of SS removal. The obtained results indicated that, using bentonite as a coagulant not only effective and economical but also, encapsulated toxic matters inside the crystals of bentonite and that makes it environmental permit compliance [10]. Aboulhassan et al., found that coagulationflocculation process using $\mathrm{FeCl}_{3}$ can be used effectively for removal of surfactants and COD from microelectronic plant wastewater and the removal efficiencies of $99 \%$ and $88 \%$ were obtained, respectively. Also they 
found that the rate of COD removal decreased if the $\mathrm{pH}$ was lower than 7 or higher than 9 [11].

This work is aimed at giving detailed description on the challenges faced when using Coagulation-flocculation method in the treatment of effluent as well as the future prospects of utilizing this method in the treatment of effluents.

\section{Coagulation and Flocculation \\ Coagulation}

Coagulation is a physical and chemical reaction occurring between the alkalinity of the water and the coagulant added to the water, which results in the formation of insoluble flocs. Polymers are also generally added with the coagulants to stimulate or improve the formation of insoluble flocs. Coagulation is the process whereby destabilization of a given suspension or solution is effected. That is, the function of coagulation is to overcome those factors which promote the stability of a given system [12]. Primary coagulant refers to that chemical or substance added to a given suspension or solution to effect destabilization [12].

Coagulation is normally accomplished through the use of chemicals known as coagulants. Coagulants used in wastewater treatment can be inorganic (such as aluminium sulphate and poly aluminium chloride), synthetic organic polymers (for example polyacrylamide derivatives and polyethylenimine) or naturally occurring coagulants (such as chitosan and microbial coagulants). Considering the types of coagulants used for wastewater treatment, some of them are harmful to human body and are very costly. To ease the problems associated with the chemical coagulants, several studies have pointed out the introduction of natural coagulants produced or extracted from microorganisms, animals, or plants [1].

Process Description: The mixing of the coagulant chemical and the raw water to be treated, suitably conditioned if necessary, is commonly referred to as flash mixing. The primary purpose of the flash mix process is to rapidly mix and equally distribute the coagulant chemical throughout the water. The entire process occurs in a very short time (several seconds), and the first results are the formation of very small particles of floc, often referred to as 'microflocs'.

Flash Mixing: Flash mixing is the first step in coagulation. The coagulant is added to the flash mixer and dispersed throughout the water. It is desirable to complete the coagulation reaction in as short a time as possible. The following is a list of flash mixing examples:

- Hydraulic mixing using flow energy 
in the system,

- Mechanical mixing,

- Diffusers and grid systems,

- Pumped blenders,

- Static mixer.

Hydraulic mixing with baffles or throttling valves works well in systems, which have sufficient water velocity to cause turbulence in the water being treated. The turbulence in the flowing water mixes the chemicals with the water.

Mechanical mixers (paddles, turbines and propellers) are frequently used in coagulation facilities. Mechanical mixers are versatile and reliable; however, they generally use the greatest amount of electrical energy for mixing the coagulant with the water being treated.

Diffusers and grid systems consisting of perforated tubes or nozzles can be used to disperse the coagulant into the water being treated. These systems can provide uniform distribution of the coagulant over the entire coagulation basin. However, they are generally sensitive to flow changes and may require frequent adjustments to produce the proper amount of mixing.

Pumped blenders have also been used for mixing in coagulation facilities. The coagulant is added directly to the water being treated through a diffuser in a pipe.
This can provide rapid dispersion of the coagulant and does not create any significant head loss in the system. Electrical energy consumption is considerably less than that of a comparable mechanical mixer.

\section{Basic Coagulant Chemistry}

Coagulation is a set of physical and chemical reactions, occurring between the alkalinity of the water, the impurities in it and the coagulant(s) added to the water, which results in the formation of insoluble flocs. These are agglomerations of the particulate suspended matter in the raw water, the reaction products of the added chemicals, as well as colloidal and dissolved matter from the water adsorbed by these reaction products.

For a specific coagulant (such as aluminium sulphate), the $\mathrm{pH}$ determines which hydrolysis species (chemical compounds) predominate. Lower $\mathrm{pH}$ values tend to favour positively charged species, which are desirable for reacting with negatively charged colloids and particulates, forming insoluble flocs and removing impurities from the water.

The optimum $\mathrm{pH}$ for alum coagulation, which is very dependant on the water being treated, usually falls in the range of $\mathrm{pH} 5$ to 8 , approximately. The aluminium hydroxide floc is insoluble over relatively narrow bands of $\mathrm{pH}$, which may vary with the source 
of the raw water. Therefore $\mathrm{pH}$ control is important in coagulation, not only in the removal of turbidity and colour but also to achieve the minimum level of dissolved residual aluminium in the clarified water. Residual alkalinity in the water serves to buffer the system (prevent $\mathrm{pH}$ from changing) and aids in the complete precipitation of the coagulant chemicals. The amount of alkalinity in the source (raw) water is generally not a problem unless the alkalinity is very low. Alkalinity may be increased by the addition of lime, caustic soda or soda ash.

Polyelectrolytes are used to improve the settling characteristics of floc produced by aluminium or iron coagulants. Generally no control is possible over the $\mathrm{pH}$ and alkalinity of the water at source. Hence, evaluation of these water quality indicators may play a major role in selecting the type of chemical coagulants to be used at a particular water treatment plant, or in changing the type of coagulant normally used if significant changes in $\mathrm{pH}$ and alkalinity occur in the raw water.

Overdosing, as well as under-dosing, of coagulants may lead to reduced solids removal efficiency. Either condition may be corrected by carefully performing jar tests and verifying process performance after making any change in the operation of the coagulation process. Similar action may be needed if a change in the quality of the source water is noted.

Optimizing Coagulation: The objective of coagulation is to condition, by chemical addition, the impurities in the water so that they will coalesce in flocculation and be removed in clarification and filtration together with the added chemicals. If the water to be treated were as constant in quality and character as groundwater from a deep well, it would theoretically be possible to calculate from analyses of the water the optimum chemical conditions and dose of coagulant required. Surface water is never as constant in quality and character as groundwater; even in a large lake, temperature changes with the season, particulate matter is blown in by wind which may also cause turbidity to increase due to disturbance of sediment. The optimum chemical conditions in terms of coagulant dose and $\mathrm{pH}$ for treatment of the water concerned are assessed by means of the jar test also called the laboratory coagulation test or the sedimentation jar test.

The commonly used metal coagulants fall into two general categories: those based on aluminium and those based on Iron. The aluminium coagulants include aluminium sulphate, aluminium chloride, polyaluminium chloride and sodium 
aluminate. The iron coagulants include ferric sulphate, ferrous sulphate, chlorinated copperas and ferric chloride. Other chemicals used as coagulants include hydrated lime, $\mathrm{Ca}(\mathrm{OH})_{2}$ and magnesium carbonate, $\mathrm{MgCO}_{3}$. The popularity of aluminium and iron coagulants arises not only from their effectiveness as coagulants but also from their ready availability and relatively low cost. The efficacy of these coagulants arises principally from their ability to form multi-charged polynuclear complexes in solution with enhanced adsorption characteristics. The nature of the complexes formed may be controlled by the $\mathrm{pH}$ of the system.

Aluminium Sulphate- $\mathrm{Al}_{2}\left(\mathrm{SO}_{4}\right)_{3.14} \mathrm{H}_{2} \mathrm{O}$ : Aluminium sulphate, probably the most widely used coagulant, is manufactured from the digestion of bauxite or aluminium ores with sulphuric acid. The quantities of bauxite used are just over the stoichiometric amounts needed to combine with the acid, so that in the final product no free acid is present. Evaporation of water in the process results in the dry product having the approximate formula $\mathrm{Al}_{2}\left(\mathrm{SO}_{4}\right)_{3} \cdot 14 \mathrm{H}_{2} \mathrm{O}$ and with an aluminium oxide $\left(\mathrm{A}_{2} \mathrm{O}_{3}\right)$ content ranging from $14 \%$ to $18 \%(\mathrm{~m} / \mathrm{m})$.

\section{Aluminium}

Chloride- $\mathrm{AlCl}_{3.6} \mathrm{H}_{2} \mathrm{O}$ :

Aluminium chloride is normally supplied in solution form containing $20 \% \mathrm{Al}_{2} \mathrm{O}_{3}$ with a
$\mathrm{pH}$ and density of approximately 2.5 and $1300 \mathrm{kgm}^{-3}$ respectively. It has been widely used for sludge conditioning and has often been described as a good general purpose conditioner. Because of hydrochloric acid (HC1) released on hydrolysis, solutions need to be stored under similar conditions to ferric chloride.

\section{Polyaluminium}

Chloride-

$\left(\mathrm{Al}(\mathrm{OH})_{1.5}\left(\mathrm{SO}_{4}\right)_{0.125} \mathrm{Cl}_{1.25}\right)_{\text {n: }}$ This coagulant, a relatively new product developed in Japan, is a partially hydrolyzed aluminium chloride incorporating a small amount of sulphate. The results obtained with this coagulant are equivalent to using aluminium sulphate in conjunction with a polyelectrolyte, although neither the precise chemical nature of the product nor the reason for its enhanced performance is perfectly understood. Approximately half the dosage is required for turbidity removal, but more or less the same dosage as aluminium sulphate is required for predominantly coloured waters. In cases where waters are predominantly turbid, therefore, use of this coagulant may significantly reduce sludge disposal problems. Polyaluminium chloride is supplied as a liquid with the equivalent of $10 \% \quad \mathrm{Al}_{2} \mathrm{O}_{3}$. Diluted solutions of concentration 0.4 - 3\% show evidence of slow hydrolysis.

Sodium aluminate-NaAlO ${ }_{2}$ : Sodium aluminate differs from alum in that it is 
alkaline rather than acidic in its reactions. It is rarely used alone, but generally with alum to obtain some special result. For example, in the coagulation of highly coloured waters, alum (plus acid usually) is added to the water to coagulate the colour at its requisite low $\mathrm{pH}$ - this, however, results in undesirable concentrations of soluble aluminium compounds; alkaline sodium aluminate is then added-also lime if required - to increase the $\mathrm{pH}$ to at least 6.0 which causes the soluble aluminium to precipitate out in a secondary settling basin.

The reactions of $\mathrm{NaAlO}_{2}$ with $\mathrm{Al}_{2}\left(\mathrm{SO}_{4}\right)_{3}\left(\mathrm{H}_{2} \mathrm{O}\right)_{14}$ and with free $\mathrm{CO}_{2}$, produce insoluble aluminium compounds, via;

$$
\begin{gathered}
6 \mathrm{NaAlO}_{2}+\mathrm{Al}_{2}\left(\mathrm{SO}_{4}\right)_{3}\left(\mathrm{H}_{2} \mathrm{O}\right)_{14} \longrightarrow \\
8 \mathrm{~A} 1(\mathrm{OH})_{3}+3 \mathrm{Na}_{2} \mathrm{SO}_{4}+2 \mathrm{H}_{2} \mathrm{O} \\
2 \mathrm{NaAlO}_{2}+\mathrm{CO}_{2}+3 \mathrm{H}_{2} \mathrm{O} \longrightarrow \\
\mathrm{Na}_{2} \mathrm{CO}_{3}+2 \mathrm{Al}(\mathrm{OH})_{3}
\end{gathered}
$$

$\mathrm{NaAlO}_{2}$, is also used in the lime-soda softening process as an aid in flocculating the fine precipitates of calcium carbonate and magnesium hydroxide resulting from the softening reactions. $\mathrm{NaAlO}_{2}$ may be purchased either as a solid or as a solution. The cost of the material is high but the required doses are small.

Ferric Sulphate- $\mathrm{Fe}_{2}\left(\mathrm{SO}_{4}\right)_{3.8} \mathrm{H}_{2} \mathrm{O}$ : This is available in solid or liquid form. In the solid form the material is granular and free flowing with the following typical specifications: $72 / 75 \% \mathrm{~m} / \mathrm{m} \mathrm{Fe}_{2}\left(\mathrm{SO}_{4}\right)_{3}$ and $20 / 21 \% \mathrm{~m} / \mathrm{m} \mathrm{Fe}^{3+}$. In the liquid form typical specifications are $40 / 42 \% \mathrm{~m} / \mathrm{m} \mathrm{Fe}_{2}\left(\mathrm{SO}_{4}\right)_{3}$ and $11.5 \% \mathrm{~m} / \mathrm{m} \mathrm{Fe}^{3+}$. Lower purity liquid grades are available with $30 \% \mathrm{~m} / \mathrm{m}$ $\mathrm{Fe}_{2}\left(\mathrm{SO}_{4}\right)_{3}$ content.

In general, all ferric coagulants are used over a wide range of $\mathrm{pH}$ from 4.0 to 11.0. Ferric sulphate is particularly useful when used for colour removal at low $\mathrm{pH}$ values and also at high $\mathrm{pH}$ values where it is used for iron and manganese removal, and in the softening process. For the latter uses the insolubility of the ferric hydroxides at high $\mathrm{pH}$ values makes the iron coagulants in general preferable to alum.

Ferrous Sulphate-FeSO ${ }_{4.7} \mathrm{H}_{2} \mathrm{O}$ : Also known as copperas (although the latter term is falling into disuse) ferrous sulphate is available either as crystals or granules containing $20 \% \mathrm{Fe}$, both of which are readily soluble in water. Ferrous sulphate reacts either with natural alkalinity or added alkalinity to form ferrous hydroxide$\mathrm{Fe}(\mathrm{OH})_{2}$, but since ferrous hydroxide is relatively soluble, it must be oxidized to ferric hydroxide in order to be useful. At $\mathrm{pH}$ values above 8.5 oxidation may be accomplished by (i) aeration; (ii) by the dissolved oxygen in the water, or, (iii) by adding chlorine. For (i) and (ii) lime must be added to obtain sufficient alkalinity. 
The important reactions for ferrous sulphate are:

$$
\begin{aligned}
& \begin{array}{l}
\mathrm{FeSO}_{4}\left(\mathrm{H}_{2} \mathrm{O}\right)_{7}+\mathrm{Ca}(\mathrm{OH})_{2} \\
\mathrm{Fe}(\mathrm{OH})_{2}+\mathrm{CaSO}_{4}+7 \mathrm{H}_{2} \mathrm{O} \\
4 \mathrm{Fe}(\mathrm{OH})_{2}+\mathrm{O}_{2}+2 \mathrm{H}_{2} \mathrm{O} \\
4 \mathrm{Fe}(\mathrm{OH})_{3}
\end{array}
\end{aligned}
$$

Ferrous sulphate and lime find their greatest use at high $\mathrm{pH}$ values; for example, the limesoda softening process and in iron and manganese removal.

Chlorinated Ferrous Sulphate: When chlorine is used to oxidize the ferrous hydroxide obtained from ferrous sulphate, the process is known as the chlorinated copperas treatment. In contrast to the high $\mathrm{pH}$ values required for oxidation by oxygen, chlorine will react over a wide $\mathrm{pH}$ range. In practice ferrous sulphate and chlorine are fed separately and are generally mixed just prior to entry into the coagulation system. The reaction with chlorine produces ferric sulphate and ferric chloride and each $\mathrm{mg} / \mathrm{l}$ of ferrous sulphate theoretically requires $0.13 \mathrm{mg} / 1$ of chlorine, although an excess of chlorine is generally added to ensure complete reaction and to provide chlorine for disinfection purposes.

The reaction is as follows:

$6 \mathrm{FeSO}_{4}\left(\mathrm{H}_{2} \mathrm{O}\right)_{7}+3 \mathrm{Cl}_{2}$

$2 \mathrm{Fe}_{2}\left(\mathrm{SO}_{4}\right)_{3}+2 \mathrm{FeCl}_{3}+7 \mathrm{H}_{2} \mathrm{O}$

Coagulation with chlorinated copperas (or ferrous sulphate) is especially useful where pre-chlorination is required. It has the further advantage over ferrous sulphate in that coagulation may be obtained over a wide range of $\mathrm{pH}$ values: 4.0 to 11.0.

Ferric Chloride - $\mathrm{FeCl}_{3}$ : Ferric chloride is available commercially in the liquid, crystal or anhydrous forms. The liquid and crystal forms are very corrosive and must be handled in a similar fashion to hydrochloric acid: for example, steel lined with fiberglass re-inforced polyester, PVC, epoxy resin, polyethylene, polypropylene, rubber or glass etc. Polyamide type plastics are not suitable. The liquid grade is supplied as a $43 \% \mathrm{FeCl}_{3}(\mathrm{~m} / \mathrm{m})$ solution. The anhydrous form may be stored in steel tanks but only if moisture is excluded. Because ferric chloride is very hygroscopic, drums must remain sealed until needed and their entire contents must be dissolved at one time.

The reactions of ferric chloride with natural or added alkalinity may be written as follows:

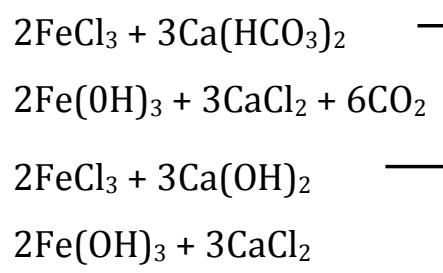

Having identified the common metal coagulants, the following discussions are devoted to the reactions taking place when metal coagulants are introduced into the stream of water to be treated. 
Aluminium and ferric salts, when in solution, immediately dissociate to form hydrated reaction products. The metal ions form coordination compounds with water molecules to give $\left\{\mathrm{Al}\left(\mathrm{H}_{2} \mathrm{O}\right)_{6}\right\}^{3+}$ and $\left\{\mathrm{Fe}\left(\mathrm{H}_{2} \mathrm{O}\right)_{6}\right\}^{3+}$. These species, referred to as the trivalent ions of aluminium and iron, are often presented as $\mathrm{Al}^{3+}$ and $\mathrm{Fe}^{3+}$ for reasons of convenience in presentation. In solution there will also be other ligands and a stepwise substitution of the ligand molecules or ions, for the water molecule takes place. The extent of this substitution depends on the concentration of the substituted ligand. For the destabilization of hydrophobic colloids with iron and aluminium coagulants, the complexes of principal interest are those comprising $\mathrm{H}_{2} \mathrm{O}$ and $\mathrm{OH}^{-}$as ligands. The $\mathrm{OH}^{-}$ligands may be thought of as arising from the dissociation of bound $\mathrm{H}_{2} \mathrm{O}$ ligands or from the replacement of $\mathrm{H}_{2} \mathrm{O}$ by $\mathrm{OH}^{-}$ligands. It can be seen that in either case, the extent to which $\mathrm{OH}^{-}$ions are bound to the metal complex is dependent primarily on the $\mathrm{pH}$ or the concentration of $\mathrm{OH}^{-}$ions in solution.

From say the first reaction, one can write:

$$
\left\{\mathrm{Al}\left(\mathrm{H}_{2} \mathrm{O}\right)_{6}\right\}^{3+} \longleftrightarrow\left\{\mathrm{Al}\left(\mathrm{H}_{2} \mathrm{O}\right)_{5} \mathrm{OH}\right\}^{2+}+\mathrm{H}^{+}
$$

From which it is seen that complexes of metal ions in water act as weak acids. Aluminium salt solutions show $\mathrm{pH}$ values similar to those of equimolar acetic acid solutions. The first ionization constant $\left(\mathrm{K}_{1}\right)$ of the aquo-ferric ion is similar to that of phosphoric acid (i.e. a $10^{-3} \mathrm{M}$ solution of $\mathrm{FeCl}_{3}$ has a pH of about 3.2).

The donor capacity of a ligand is frequently not exhausted by being co-ordinated to a metal ion and there is a possibility of it forming a co-ordinative bond with another metal ion. The ligand thus acts as a bridge between the two central ions. Both unidentate and multidentate ligands may serve as bridges in polynuclear complexes.

Both iron and aluminium-hydroxo complexes have pronounced tendencies to form polynuclear complexes. The simplest reaction leading to a bi-nuclear iron complex species is:

$2\left\{\mathrm{Fe}\left(\mathrm{H}_{2} \mathrm{O}\right)_{5}(\mathrm{OH})\right\}^{2+}$

$\left(\mathrm{Fe}_{2}\left(\mathrm{H}_{2} \mathrm{O}\right)_{8}(\mathrm{OH})_{2}\right\}^{4+}+2 \mathrm{H}_{2} \mathrm{O}$

The bi-nuclear ion so formed has sufficient stability to exist in appreciable concentrations in iron solutions which are more concentrated than $10^{-4} \mathrm{M}$.

Polymers (also known as polyelectrolytes) are the most commonly used coagulant aids in the NWT. They are synthetic, high molecular weight organic compounds. They are used to make flocs:

- Bigger

- Stronger

- More settable under difficult 
treatment conditions.

Polymers act similarly coagulants in that they bind to the particles in water through a difference in electrical charge between the particle and the polymer. This is how polymers are classified into three different groups, by their different charges:

- Anionic: having a negative charge

- Cationic: having a positive charge

- Nonionic: having no charge

\section{Flocculation}

The process of forming large agglomerates of particles in suspension or of small agglomerates already formed as a result of coagulation through gentle stirring or agitation is called flocculation [1].

Flocculation is the process whereby destabilized particles, or particles formed as a result of destabilization, are induced to come together, make contact and thereby form large(r) agglomerates [12].

Flocculation is the slow stirring process that causes the gathering together of small, coagulated particles into larger, settleable particles. Once gathered together into floc, the floc is easily removed by sedimentation and filtration. The collision between particles, or the gathering of particles, occurs because of gentle stirring by a mechanical or hydraulic means of mixing. Floc formation is controlled by the rate at which collisions occur between particles and by the effectiveness of these collisions in promoting attachment between particles. The purpose of flocculation is to create a floc of a good size, density, and toughness for later removal in the sedimentation and filtration processes. The best floc size ranges from $0.1 \mathrm{~mm}$ to about $3 \mathrm{~mm}$, depending on the type of removal processes used. If algae are present in large numbers in the water, the floc will have a stringy appearance.

The flocculation process provides conditions for contact between particles to promote their gathering together into flocs for ease of removal, mainly by clarification and finally by filtration. These contacts or collisions between particles result from gentle stirring created by a mechanical or other means of mixing, at a rate much slower than the mixing rate in coagulation, sometimes in dedicated flocculation basins. In hopper-bottomed upward-flow basins which utilize the sludge blanket affect these contacts or collisions between particles result from hydraulic mixing.

Floc formation is controlled by the rate at which collisions occur between particles and by the effectiveness of these collisions in promoting attachment between particles. The purpose of flocculation is to create a floc of a suitable size, density, and toughness for later removal in the sedimentation and filtration processes. The best floc size ranges 
from $0.1 \mathrm{~mm}$ to about $3 \mathrm{~mm}$, depending on the type of removal processes used, the smaller floc size being best suited to direct filtration and the larger to removal by clarification.

Some flocculation can be accomplished by the turbulence resulting from the roughness in conduits or channels, or by the dissipated energy of head losses associated with weirs, baffles and orifices. Generally, these methods find only limited use owing to disadvantages such as much localized distribution of turbulence, inadequate detention time, and widely variable turbulence resulting from flow fluctuations.

Flocculant aids are those chemicals or substances added to a destabilized suspension or solution to accelerate the rate of flocculation or to strengthen flocs formed during flocculation [12].

There are two stages in the flocculation process: The first, given the name perikinetio flocculation, arises from thermal agitation (Brownian movement) and is a naturally random process. Flocculation during this stage commences immediately after destabilization and is complete within seconds since there is a limiting floc size beyond which Brownian motion has no or little effect.

Furthermore, although the potential energy barrier existing between colloidal particles may be overcome by the thermal kinetic energy of Brownian movement, as the particles progressively coalesce the magnitude of the energy barrier increases approximately proportional to the area of the floe, so that eventually perikinetic flocculation of such potentially repellant particles must cease.

The rate of flocculation or the rate of decrease in the number of particles of a suspension due to perikinetic flocculation may be described by a second order rate law. For example, in turbid water containing $10^{6}$ particles per $\mathrm{mL}$, the particle number concentration would be reduced by half within a period of about 6 days; provided all the particles were completely destabilized and the particles did not become too large and be outside the range of Brownian movement.

The second stage in the flocculation process is given the name orthokinetia flocculation and arises from induced velocity gradients in the liquid. Such velocity gradients may be induced by setting the liquid in motion by;

(a) Passage around baffles or mechanical agitation within a flocculation reactor;

(b) The tortuous path through interstices of a granular filter bed;

(c) Where flocs are sufficiently formed, by sedimentation within a settling basin and so on. The effect of velocity gradients within a 
body of liquid is to set up relative velocities between particles thereby providing opportunity for contact.

For a given flocculating system, the principal parameter governing the rate of orthokinetic flocculation is the velocity gradient applied. The degree or extent of flocculation is governed by both applied velocity gradients and time of flocculation. These two parameters influence the rate and extent of particle aggregation and the rate and extent of breakup of these aggregates.

Although the floc formed contains most of the suspended matter in the water, it is still made up of approximately 96\% water. Because of this, it is very fragile and must be treated gently. This means that high-speed flocculation must be avoided. An efficient flocculation process involves the selection of the right stirring time (detention time), the proper stirring intensity, a properly shaped basin for uniform mixing, and mechanical equipment or other means of creating the stirring action.

Detention time is required for the necessary chemical reactions to take place. Detention time is usually not a critical factor in the coagulation or flash-mixing process, if the chemical coagulants are well dispersed into the water being treated and mixed for at least several seconds. In the NWT, since we have different types of packaged treatment plants, the retention time varies from one plant to the next. The minimum detention time recommended for flocculation ranges from about 5 to 20 minutes for direct filtration systems and up to 30 minutes for conventional filtration. The size and shape of the flocculation facility also influences the detention time needed for optimum floc development. Some operators have been able to reduce coagulant dosages by increasing the amount of detention time between the point of addition of the coagulant and the flocculation basins.

\section{Flocculators}

Two types of mechanical flocculators are commonly installed:

1. Horizontal paddle wheel types; and

2. Vertical flocculators.

Both types can provide satisfactory performance; however, the vertical flocculators usually require less maintenance, since they eliminate submerged bearings and packings. Vertical flocculators can be of the propeller, paddle, or turbine types. The best flocculation is usually achieved in more than one compartmentalized basin rather than one equivalent-sized basin. The compartments are separated by baffles to prevent shortcircuiting of the water being treated, and to reduce the level of turbulence in each succeeding compartment by reducing the 
speed of the stirrers, or reducing the area of the paddles. This is called "tapered-energy mixing". The reason for reducing the speed of the stirrers is to prevent breaking apart the large floc particles that have already been formed. Breaking up the floc will not accomplish anything, reduces the efficiency of the settling, and will overload the filters because not as many flocs will be settled out in sedimentation.

\section{The Coagulation and Flocculation Process}

The efficiency of the coagulationflocculation process is dependent on many variables. For particular water these include:

(i) type of coagulant used

(ii) coagulant dosage

(iii) final $\mathrm{pH}$

(iv) coagulant feed concentration

(v) Type and dosage of chemical additives other than primary coagulant (e.g. polyelectrolytes, etc.)

(vi) sequence of chemical addition and time lag between dosing points

(vii) intensity and duration of mixing at rapid mix stage

(viii) type of rapid mix device

(ix) velocity gradients applied during flocculation stage

(x) flocculator retention time (xi) type of stirring device used

(xii) Flocculator geometry.

To adequately assess the optimum conditions for the overall process it is necessary to use a testing procedure which sequentially maintains each parameter constant while the optimum value of a particular parameter is determined.

The pre-requisite for such a series of tests is, if possible, to thoroughly analyse the water and thereby identify the impurities most requiring consideration. In many cases the impurities of major concern are colour and/or turbidity, but in others residual phosphorus, iron, viruses and so on may be the governing criterion. The particular application obviously decides the desired final water quality and, therefore, the combination of coagulation-flocculation variables most appropriate. In some instances, tests must be carried out on a water or wastewater with unknown characteristics. Although an a priori estimation of the likely range of process variables in such cases is not possible, the testing procedure remains essentially the same. With some applications final effluent quality is not of major importance; an example is with sludge conditioning where the specific resistance or capillary suction time of the sludge after treatment is of concern. 
The apparatus used for assessing the performance of a particular primary coagulant is the standard jar test apparatus. It consists essentially of a rack of stirrers, driven by one motor, under which $600 \mathrm{~mL}$ or preferably 1 liter glass beakers are arranged. Beakers of lesser capacity than $600 \mathrm{~mL}$ should not be used since irreproducible results may occur due to difficulties in accurately adding coagulants or coagulant aids. Furthermore, where the test criterion is settling velocity, tall beakers of large capacity are to be preferred. When using polyelectrolytes either as primary coagulants or coagulant aids, the inner surfaces of the beakers serve as adsorption sites for the polymer. The effect is accentuated when smaller beakers are used and for waters of low turbidities where the total colloidal surface area may be of the same order of magnitude as the beaker inner surface area. For this reason beakers of at least $1 \%$ capacity are recommended.

The speed of rotation of the stirrers on the jar test apparatus is variable using, in almost all cases of proprietary equipment, a thyristor speed control connected to the motor. A variable speed facility is required because a fast speed is used during coagulant addition and a slow speed or the flocculation phase. Speed variation using a thyristor control (which varies the speed of the motor) is perhaps not the best method since the speed is often not exactly reproducible at a particular dial setting. More satisfactory is a constant speed motor with some form of gear or pulley arrangement. Light source arranged either above or below the beakers (e.g. a daylight 'cold' fluorescent tube). A black background to the beakers is also useful; (ii) flat bladed stirrers rather than the propellor type; (iii) a rack of, for example, test tubes spaced so as to coincide with the position of the beakers and thus facilitate simultaneous chemical addition. Addition of coagulant should be rapid and the stirring should be such that dispersion occurs in as short a time as possible.

\section{Jar Test Procedure}

The jar test procedure involves the following steps:

- Fill the jar testing apparatus containers with sample water. One container will be used as a control while the other 5 containers can be adjusted depending on what conditions are being tested. For example, the $\mathrm{pH}$ of the jars can be adjusted or variations of coagulant dosages can be added to determine optimum operating conditions.

- $\quad$ Add the coagulant to each container and stir at approximately $100 \mathrm{rpm}$ for 1 minute. The rapid mix stage helps to disperse the coagulant throughout each 
container.

- Turn off the mixers and allow the containers to settle for 30 to 45 minutes. Then measure the final turbidity in each container.

- $\quad$ Reduce the stirring speed to 25 to 35 rpm and continue mixing for 15 to 20 minutes. This slower mixing speed helps promote floc formation by enhancing particle collisions which lead to larger flocs.

- $\quad$ Residual turbidity vs. coagulant dose is then plotted and optimal conditions are determined. The values that are obtained through the experiment are correlated and adjusted in order to account for the actual treatment system.

\section{Merits and Demerits of Coagulation-} Flocculation Method

\section{Merits of the Coagulation-Flocculation}

\section{Method}

- The coagulation and flocculation processes are required to precondition or prepare non-settleable particles present in the raw water for removal by sedimentation and filtration. Small particles, without proper coagulation and flocculation are too light to settle out and will not be large enough to

- $\quad$ Be trapped during filtration. In this regard it is convenient to consider coagulation-flocculation as one treatment process.

- $\quad$ Since the purpose of coagulationflocculation is to promote particulate removal, the effectiveness of the sedimentation and filtration processes, as well as overall plant performance, depend upon successful coagulation-flocculation. Disinfection of the water can also be affected by poor coagulation-flocculation performance. Bacteria and other diseasecausing organisms can be bound up in suspended particles and thereby shielded from disinfection if the solids removal processes before final disinfection, especially filtration, are ineffective. Effective coagulation-flocculation promotes the removal of natural organic compounds. Removal of these compounds will reduce the formation of trihalomethanes following the use of chlorine for disinfection.

Phosphate Removal: Phosphorus removals in excess of 90 per cent may be obtained through coagulation. Thus where coagulation is used, phosphorus removal may be achieved as a side benefit. It has been found that the aluminum ion feed rate for phosphate removal is directly proportional on a weight basis to the phosphate concentration. Thus for domestic sewage (10-20 mg/L P) an alum feed rate of 100- 
$200 \mathrm{mg} / \mathrm{L}$ will provide high phosphorus removals.

- Inorganic salts of multivalent metals such as alum, polyaluminium chloride, ferric chloride, ferrous sulphate, calcium chloride and magnesium chloride have been widely used for decades as coagulant. It is mainly because of its advantage of low cost, where their market price is very much lower compared to the chemical flocculants, availability, and ease in handling. Alum treatment does not interfere with the operation of following biological process such as anaerobic sludge digestion and activated sludge.

\section{Challenges/Demerits of the Coagulation-}

\section{Flocculation Method}

Iron compounds have not been widely used as a primary coagulant probably because of color problems and oxidation - reduction reactions which may take place.

Alum is the most widely used coagulant. However, the demerits of using Alum are;

- $\quad$ May cause ponding if carried over onto a trickling filter process.

- $\mathrm{SO}_{4}{ }^{2-}$ compounds in the sludge may be reduced to $\mathrm{H}_{2} \mathrm{~S}$ in anaerobic sludge digestion process causing severe corrosive problems in gas piping and equipment.

- Use of alum will result in an increase in the total solids (sodium and sulfates) content of plant effluent.

- $\quad$ Neutralization may be needed after the coagulation process resulting in higher chemical costs.

Sodium aluminate offers a possible solution to some of the difficulties associated with alum. Sodium aluminate $\left(\mathrm{Na}_{2} \mathrm{Al}_{2} \mathrm{O}_{4}, 62-72 \%\right.$ dry, 33-46\% liquid) contains nearly two and one half times the amount of aluminum ion on a weight basis $(22.5 \%$ compared to $9 \%$ for dry form, $14.1 \%$ compared to $4.4 \%$ for liquid form). Thus if coagulation is a function of the metal ions a lesser amount of aluminate would be required. The problems of sulfate compounds do not exist. 1\% solution of dry sodium aluminate has a $\mathrm{pH}$ of 11.5 to 12.0 . Since a significantly lesser amount of aluminate may be required, $\mathrm{pH}$ adjustment may not be required after the coagulation process. The major problems with sodium aluminate are:

- Cost

- Availability

- Viscosity in solution

Manufacture of sodium aluminate is limited; however, there is some indication that increased use in the public works field may result in more competitive pricing and Improved availability.

Solutions of sodium aluminate are very viscose and present pumping difficulties at 
temperatures much less than $80^{\circ} \mathrm{F}$ unless in dilute solutions.

Recent epidemiological, neuropathological and biochemical studies suggest a possible link between the neurotoxicity of Aluminium and the pathogenesis of Alzheimer's disease, Chitosan is exact replacement for aluminum based coagulants. Chitosan was more ecofriendly characteristic and bio degradable polymer [13].

The application of inorganic coagulants in wastewater is quite limited nowadays and has been reduced due to numerous disadvantages. As reported in many studies, its usage would cause two important environmental consequences which are the production of large volumes of metal hydroxide (toxic) sludge which will create disposal problem and an increase in metal (e.g., aluminium) concentration in the treated water which may have human health implications. Other drawbacks include large amount is required for efficient flocculation, highly sensitive to $\mathrm{pH}$, inefficient towards very fine particles, inefficient in cold water (e.g. polyaluminium chloride) and applicable only to a few disperse systems [12]. In order to minimize the drawbacks of inorganic flocculants, many factors have been taken into consideration to find the alternative and reduce the dosage of the harmful inorganic flocculants.

The extensive use of polymers as flocculant is due to their distinct characteristic attributes. The polymers are convenient to use, immediately soluble in aqueous systems, and do not affect the $\mathrm{pH}$ of the medium. They are highly efficient with little quantities (e.g. mg/L) and the flocs formed during flocculation are bigger and stronger. Normally, an appropriate polyelectrolyte can increase floc size, and thus form. Although water soluble synthetic polymers find wide applications as flocculants, however its market cost is at least ten times higher compared to chemical coagulants which influences its development. In addition, their usage is debatable because its application may cause environmental consequences and health hazards.

Even though bio-flocculants displayed promising flocculating efficiency in treatment of different types of waste water but its future development is constrained by some disadvantages. Natural polymers have shorter shelf life because its active components will biodegrade with time and thus needs to be suitably controlled. Furthermore, the flocs tend to lose stability and strength with time because of their biodegradability. Most biodegradable natural and biopolymers contain hydrolysable groups along with the main 
chain which can cause biodegradation to happen via hydrolysis. In addition, some of the anionic bioflocculants (e.g., tannin, cellulose, and alginate) are moderately effective and only can be utilized as coagulant aid. In the coagulationflocculation process, cationic coagulant is required for charge neutralization before bio-flocculant could bridge the micro-flocs together and high dosage is needed to achieve efficient flocculation. Hence, in order to address all these concerns, new generation of polymeric flocculants has been developed by optimally grafting synthetic polymeric branches onto purified polysaccharide backbone [9].

\section{Conclusion and Future Perspective}

The potential application of conventional flocculants and Coagulants in wastewater treatment has been verified and research is still ongoing. They have shown remarkable results in reduction or removal of environmental concerned parameters such as TSS, turbidity, COD and colour and it was discovered that a wide range of removal was achieved in some of the studies. Although many flocculating materials have been developed and successfully used in removing pollutants from wastewater in laboratory scale, there is still a need to improve their performance in removal of suspended and dissolved impurities, heavy metals, and colour or dye molecules, inorganic or organic pollutants in order to meet the environmental legislation before the wastewater is discharged to the environment. Considering the industrial dependencies on the cost effective flocculation technology for wastewater treatment, it is required to conduct more future research for best flocculants which is capable to produce very promising results in pollutants removal even at wider variations of $\mathrm{pH}$ and other contaminants of the wastewater. For chemical flocculants, the flocculation optimization practices in the industry are still scarce because of the highly complex nature of the flocculation process and the large variety of polyelectrolytes available. One of the ways to optimize the flocculation process is by selecting or controlling the range of the molecular weight and the charge density of the polymer. Different molecular weights and charge density produce different flocculation mechanisms (neutralization or bridging). Future research needs to look into how molecular weight and charge density distribution affect the flocculation performance to produce a better choice of flocculants for specific industrial applications. Optimization of these factors could significantly increase the treatment efficiency and reduce the chemical cost. Since the usage of conventional flocculants 
is closely related with environmental pollution and health hazards, synthesis of environmental friendly and economic viable flocculants that exhibit high flocculating efficiency is highly desirable. .In addition, very limited work has been carried out on the industrial scale, mostly is concentrated in laboratory testing. The complexity of the coagulation and flocculation systems justifies that a polymer cannot be selected for a given application without experimental testing. This testing involves two stages: (i) laboratory tests for selecting the type of flocculants and more particularly the optimum ionicity and (ii) industrial trials or practices for confirming the flocculants election and for determining its amount and its molecular weight. At last but not least, the selection of high efficient flocculants that could nearly remove or reduce all of the contaminants in wastewater is essential for a successful flocculation process. Environmental friendly flocculants that can be produced by simple and economically viable process which exhibits high removal efficiencies and considerably denser flocs is regarded as a promising material in real application from the perspective of both performance and cost.

\section{ORCID}

Kingsley Ogemdi Iwuozor (iD): 0000-0002-1161$\underline{2147}$

\section{References}

[1]. R.R. Ayangunna, S.O. Giwa, A. Giwa, Int. J. ChemTech Res., 2016, 9, 771-780.

[2]. A. Aygun, T. Yilmaz, Int. J. Chem. Environ. Eng., 2010, 1, 97-101.

[3]. S.H Lin, W.Y. Liu, Int. Res. J. Environ. Sci., 1994, 2, 25-29.

[4]. M. Riera-Torres, C. Gutiérrez-Bouzán, M. Crespi, Int. Res. J. Environ. Sci., 2010, 31, 717731.

[5]. R. Krishna, O. Sahu, J. Polym. Biopolym. Phys. Chem., 2013, 1, 22-25.

[6]. C. Patil, M. Hugar, Int. Res. J. Eng. Technol., 2015, 2, 1120-1124.

[7]. J. M. Prodanovic, M. B. Sciban, M.G. Antov, J. M. Dodic, Romanian Biotechnol. Lett., 2011, 16, 6638-6647.

[8]. T. Kazi, A. Virupakshi, Int. J. Innovat. Res. Sci., Eng. Technol., 2013, 2, 4061-4068.

[9]. M.O. Fatehah, S. Hossain, T.T. Teng, J. Water Resource Protect., 2013, 5, 10181026.

[10]. A.M. Abdelaal Eighth International Water Technology Conference in Faculty of Petroleum and Mining Engineering, Suez Canal University, Suez, Egypt, 2004, 1, 781791.

[11]. M.A. Aboulhassan, S. Souabi, A. Yaacoubi, M. Baudu, Int. J. Environ. Sci. Tech., 2006, 3, 327-332.

[12]. J. Bratby, Coagulation and Flocculation with an emphasis on water and wastewater 
treatment, Uplands press publication [13]. L.N. Rao, Int. J. Eng. Appl. Sci., 2015, 2, limited: England. pp. 55-61, 264-266. 50-52.

How to cite this manuscript: Kingsley Ogemdi Iwuozor, Prospects and Challenges of Using Coagulation-Flocculation Method in the Treatment of Effluents , Adv. J. Chem. A, 2019, 2(2), 105-127. 